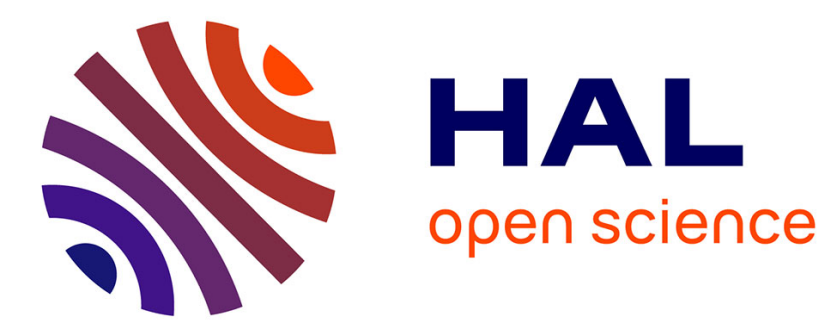

\title{
Plate modes in piezoelectric multilayered structures
}

\author{
E.L. Adler, A.A. Nassar
}

\section{To cite this version:}

E.L. Adler, A.A. Nassar. Plate modes in piezoelectric multilayered structures. Revue de Physique Appliquée, 1985, 20 (6), pp.311-317. 10.1051/rphysap:01985002006031100 . jpa-00245338

\section{HAL Id: jpa-00245338 https://hal.science/jpa-00245338}

Submitted on 1 Jan 1985

HAL is a multi-disciplinary open access archive for the deposit and dissemination of scientific research documents, whether they are published or not. The documents may come from teaching and research institutions in France or abroad, or from public or private research centers.
L'archive ouverte pluridisciplinaire HAL, est destinée au dépôt et à la diffusion de documents scientifiques de niveau recherche, publiés ou non, émanant des établissements d'enseignement et de recherche français ou étrangers, des laboratoires publics ou privés. 


\title{
Plate modes in piezoelectric multilayered structures
}

\author{
E. L. Adler and A. A. Nassar \\ Department of Electrical Engineering, McGill University, \\ 3840 University Street, Montréal, Québec H3A 2A7, Canada
}

(Reçu le 20 juillet 1984, accepté le 15 octobre 1984)

\begin{abstract}
Résumé. - Des expériences récentes ont montré que des transducteurs interdigités pouvaient exciter fortement des modes de plaque dans des membranes composites piézoélectriques. Dans cet article, on présente les propriétés dispersives et le couplage piézoélectrique $(\Delta v / v)$ de ces modes de plaque. Les différents types de modes sont identifiés et reliés à la symétrie cristalline. Des résultats sont donnés pour les modes transverses durcis dans des membranes d'oxyde de zinc et de sélénium et pour les modes de Lamb durcis, dans des membranes de ZnO et Se comme dans celles des plaques composites $\mathrm{ZnO}$ sur $\mathrm{Si}$ et $\mathrm{ZnO}$ sur GaAs.

Des valeurs de coefficients $\Delta v / v$ comprises entre un et huit pour cent se révèlent typiques de tels modes de plaques. Des détails sur les facteurs de couplage, les caractéristiques de dispersion et les propriétés de bande passante qui illustrent les propriétés de ces modes sont donnés dans l'article.
\end{abstract}

\begin{abstract}
Recent experiments have shown that interdigital transducers can couple strongly to plate modes in piezoelectric composite membranes. In this paper the dispersive properties and the piezoelectric coupling $(\Delta v / v)$ to these plate modes are presented. The various types of modes are identified and related to crystalline symmetry. Results are given for stiffened-shear modes in zinc oxide and selenium membranes and for stiffened-Lamb modes in $\mathrm{ZnO}$ and Se membranes as well as in $\mathrm{ZnO}$-on-Si and $\mathrm{ZnO}-o n-G a A s$, composite plates. Piezoelectric coupling $(\Delta v / v)$ values ranging from one to eight percent are found to be typical for such plate modes. Details of coupling factors, dispersion characteristics, and passband properties which illustrate the properties of these modes are given.
\end{abstract}

\section{Introduction.}

The general term plate mode or plate-mode waves is used to describe acoustic waves that propagate parallel to the free surfaces of a plate. In ultrasonic devices which utilize such waves the plate is usually cut from a pure crystal and is often piezoelectric. These modes can exist in plates with thicknesses ranging from many times the acoustic wavelength to thicknesses much smaller than that wavelength. In the former case, the plate is usually meant for surface-acoustic-wave (SAW) applications and the study of the spectrum of these plate modes [1] is important in evaluating spurious signals associated with SAW devices. It is the latter case, that of acoustically-thin plates or membranes, which is the subject of this article.

The choice of a thin membrane reduces the number of plate modes that can propagate unattenuated within a certain bandwidth. Membranes with thicknesses as small as $1 / 40$ wavelength have been fabricated [2] for the generation and propagation of plate modes at frequencies as low as $1.3 \mathrm{MHz}$, corresponding to a very low phase velocity of only $184 \mathrm{~m} / \mathrm{s}$. Other possible advantages of using membrane structures over the conventional «thick » SAW devices include improved coupling to interdigital transducers (IDT's) resulting in a lower insertion loss and a higher frequency of operation using the same transducer periodicity [3].

Calculations of electromechanical coupling, represented by the fractional change in velocity due to surface metallization, $\Delta V / V$, for plate modes in piezoelectric membranes such as zinc oxide $(\mathrm{ZnO})$ and selenium (Se) membranes [4] have shown that large $\Delta V / V$ 's (of the order of a few percent) are commonly obtained with plate modes. These calculations were carried out using a general computer program that was developed [5] for the study of plate modes in multilayered membranes of arbitrary orientations and interface conditions.

In this paper we first review some of the important characteristics of plate-mode propagation in both simple and composite (or multilayered) membranes. 
These include phase and group velocity (dispersion characteristics), mode spectra and $\Delta V / V$. Examples that include $\mathrm{ZnO}$ and $\mathrm{Se}$ membranes as well as $\mathrm{Se} / \mathrm{Te}$, $\mathrm{ZnO} / \mathrm{Si}$, and $\mathrm{ZnO} / \mathrm{GaAs}$ composite membranes are given to illustrate the main characteristics of these modes. The specific modes studied are of the stiffenedLamb (S.-L.) and the stiffened-shear (S.-S.) types.

The classification that is used here to identify the different types of plate modes is based on which of the mechanical and electrical components are coupled together in the wave, and is presented in the next section. This is followed by discussions of stiffenedshear mode examples in section 3 and stiffened-Lamb mode examples in section 4 .

\section{Types of plate modes.}

The plate illustrated in figure 1 shows the geometry and coordinate system convention for a typical platemode or membrane device. Both the width and the length are much larger than the acoustic wavelength, $\lambda$, while the thickness $h$ is, at most, a few wavelengths and can be as small as a small fraction of $\lambda$. The transducers are placed on one of the two free surfaces (normal to $X_{3}$ ) and the wave is assumed to be propagating along $X_{1}$ parallel to these free surfaces. The $X_{1} X_{3}$ plane is called the sagittal plane and the mechanical displacements $u_{1}$ and $u_{3}$ are termed the sagittalplane displacements. The displacement $u_{2}$ is the transverse displacement and $\phi$ the electric potential. The four variables $u_{1}, u_{2}, u_{3}, \phi$ are the components of the wave and the wave type [5] depends on which of these components are intercoupled. This intercoupling is determined by the material crystalline symmetry and the particular orientation of the free surface of the plate and the propagation direction with respect to the material crystalline axes. The detailed

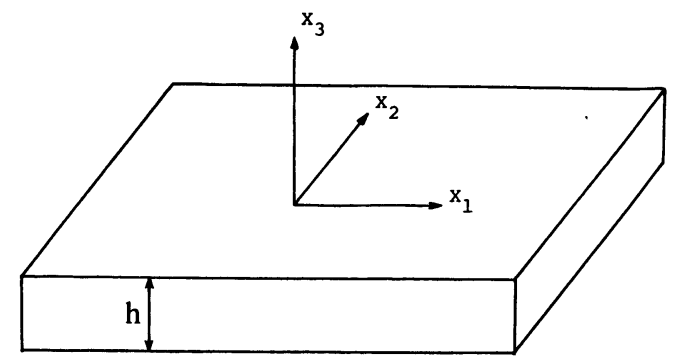

Fig. 1. - The geometry of a plate or membrane. The sagittal plane is the $X_{1} X_{3}$ plane and propagation is along the $X_{1}$ direction.

discussions of the symmetry in different crystal groups is given in reference [6]. Here we summarize the terms used for the different types of plate modes by referring to table I. The numerical entries in the first column of table I are the symmetry classification given in reference [6]. In the second column the coupled components are grouped together in separate lines, with two lines for one symmetry type indicating that for that particular type, the wave components have separated into two independent coupled groups. For example symmetry type 4 consists of two independent coupled groups, a sagittal mechanical and a transverse piezoelectric. The terms given in column 3 are those used in [5] and in the last column examples are given. The term general indicates the presence of all the three mechanical displacement and the electric potential; the term stiffened is used to indicate that piezoelectric coupling exists between the mechanical variable(s) and the electric potential.

In a plate of a particular thickness $h$, an infinite number of modes can propagate for each allowed type of wave. The velocity of each mode can be calculated as a continuous function of either the thickness-towavelength ratio $h / \lambda$ or the thickness-frequency pro-

Table I. - Types of plate modes $[5,6]$

\begin{tabular}{|c|l|l|l|}
\hline Symmetry class [6] & Coupled components & Type of wave [5] & \multicolumn{1}{|c|}{$\begin{array}{c}\text { Examples of } \\
\text { crystalline symmetry }\end{array}$} \\
\hline 1 & $u_{1}, u_{2}, u_{3}, \phi$ & general & $\begin{array}{c}\text { Trigonal 32, Y-cut, } X \text {-propa- } \\
\text { gation (e.g. quartz) }\end{array}$ \\
\hline 2 & $u_{1}, u_{2}, u_{3}$ & general mechanical & $\begin{array}{l}\text { Trigonal } \overline{3} \text { class (any principal } \\
\text { direction in a principal plane) }\end{array}$ \\
\hline 3 & $\begin{array}{l}\text { a) } u_{1}, u_{3}, \phi \\
\text { b) } u_{2}\end{array}$ & $\begin{array}{l}\text { a) stiffened-Lamb } \\
\text { b) shear }\end{array}$ & $\begin{array}{l}\text { Hexagonal 6 mm, Z-cut, any } \\
\text { direction (e.g. ZnO) }\end{array}$ \\
\hline 4 & $\begin{array}{l}\text { a) } u_{1}, u_{3} \\
\text { b) } u_{2}, \phi\end{array}$ & $\begin{array}{l}\text { a) Lamb } \\
\text { b) stiffened-shear }\end{array}$ & $\begin{array}{l}\text { Trigonal 32, Z-cut, Y-propa- } \\
\text { gation (e.g. selenium) }\end{array}$ \\
\hline 5 & $\begin{array}{l}\text { a) } u_{1}, u_{3} \\
\text { b) } u_{2}\end{array}$ & $\begin{array}{l}\text { a) Lamb } \\
\text { b) shear }\end{array}$ & Isotropic \\
\hline
\end{tabular}


duct hf. Most of the modes are high-pass, i.e., have a cutoff frequency, which means that for a given plate thickness unattenuated propagation can only occur above a certain frequency called the cutoff frequency. For the examples studied there are two all-pass modes for the stiffened-Lamb and one for the stiffened-shear type.

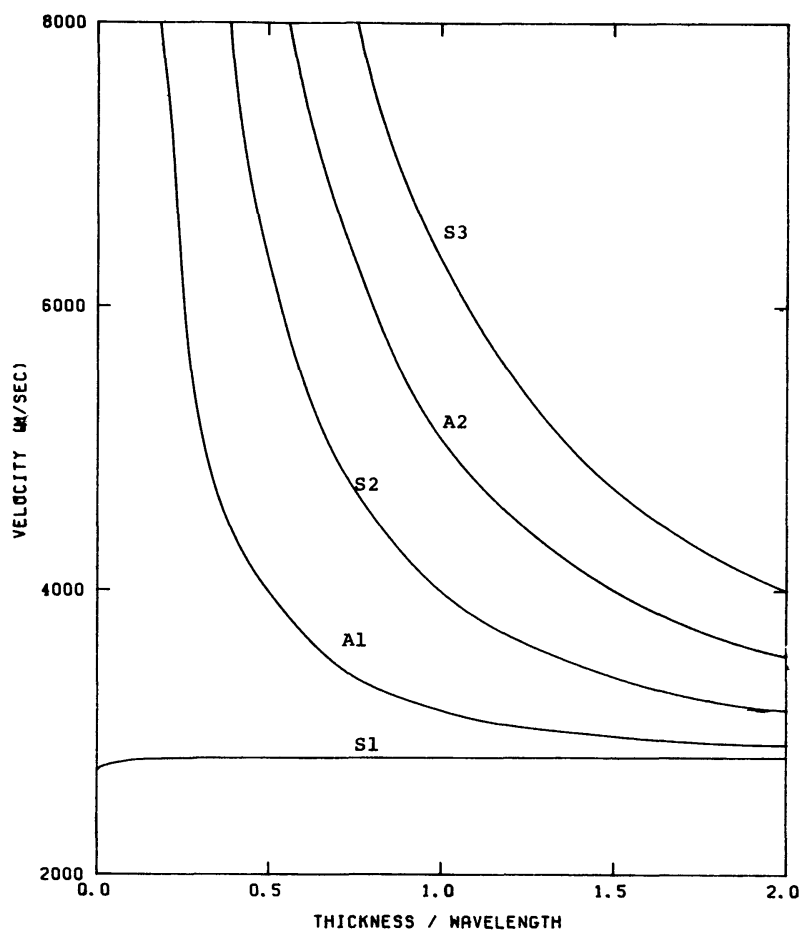

Fig. 2. - Wave velocity versus $h / \lambda$ for the first five stiffenedshear modes in a $\mathrm{ZnO}$ membrane. The membrane is $Y$-cut and propagation is along the $X$ axis.

In figure 2 , the phase velocities of the first five stiffened-shear modes in $\mathrm{ZnO}$ membranes are shown, the free surfaces of the membrane are parallel to the crystalline $\mathrm{XZ}$ plane and propagation is along the $X$ axis. The modes are labelled $S$, for symmetrical and A for antisymmetrical. This refers to the amplitude profile of the transverse displacement $u_{2}$ as illustrated in figure 3. The profiles are either symmetrical or antisymmetrical with respect to the center plane of the membrane. The first symmetrical mode (S1) is an all-pass mode, i.e. it can propagate at any frequency, while all the other modes are high-pass modes. It can be seen that the $\mathrm{S} 1$ mode has negligible velocity dispersion. An example of the velocity characteristics of another type of plate mode, the stiffened-Lamb mode, is given in figure 4. The $\mathrm{ZnO}$ membrane is now oriented with the free surfaces parallel to the $X Y$ plane (a $Z$-cut surface). There are two all-pass modes here, the first symmetrical and the first antisymmetrical. These terms now refer to the profiles of the sagittal-plane displacement $u_{1}$. In the next two sections these modes; as well as those of figure 2 , are discussed in detail.

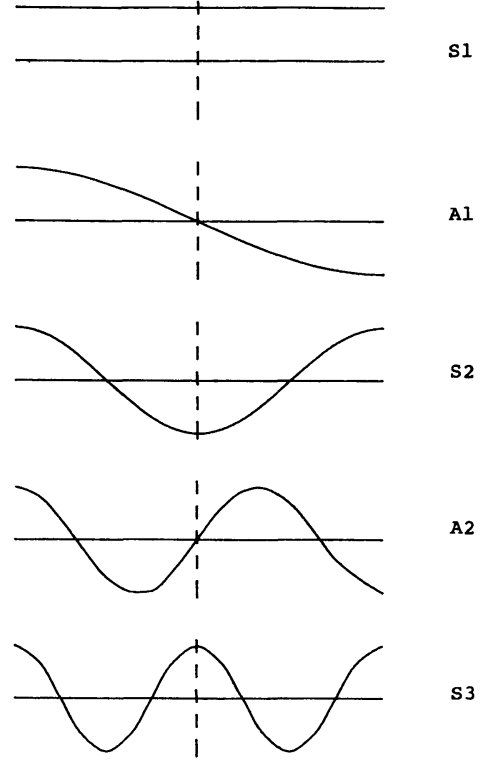

Fig. 3. - Thickness profiles of $u_{2}$ for the first five stiffenedshear modes of figure 2 . The dashed lines represent the centre plane of the membrane.

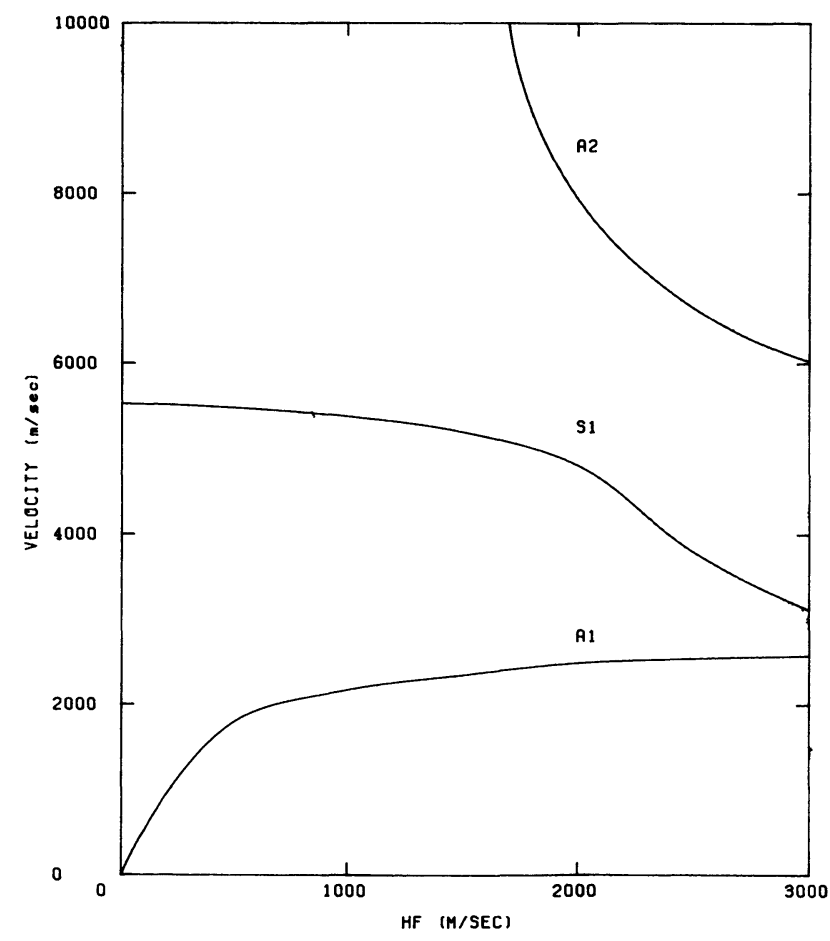

Fig. 4. - Velocities of the first three stiffened-Lamb modes in a $\mathrm{Z}$-cut $\mathrm{ZnO}$ membrane as functions of the thicknessfrequency product.

\section{Stiffened-shear modes.}

The examples given here include zinc oxide and selenium membranes as well as the selenium/telluruim composite membrane. The phase velocity for each of the five lowest modes is given in figure 2 for the $\mathrm{ZnO}$ 
membrane. These curves showing velocity versus $h$ are calculated directly using the plate-mode computer program [5]. These curves contain the essential information on the dispersion characteristics of each of the modes and are basic to the design of any plate-mode structure. Another useful way of describing the dispersion characteristics is the $\omega-\beta$ or $\frac{\omega h}{2 \pi}-\frac{\beta h}{2 \pi}$ curve. Such curves are shown in figure 5 where the five curves are obtained from the corresponding mode curves of figure 2 . Using $\beta=2 \pi / \lambda$, one obtains the relations

$$
\frac{\beta h}{2 \pi}=\frac{h}{\lambda}, \frac{\omega h}{2 \pi}=\left(\frac{h}{\lambda}\right) V_{\mathrm{p}},
$$

where $V_{\mathrm{p}}$ is the phase velocity. This form of presentation has the advantage of directly showing the cutoff frequency of each mode at the intersection of the corresponding curve and the vertical axis. For example for a $100 \mu \mathrm{m}$ membrane the cutoff frequency of the S2 mode is approximately $28 \mathrm{MHz}$.

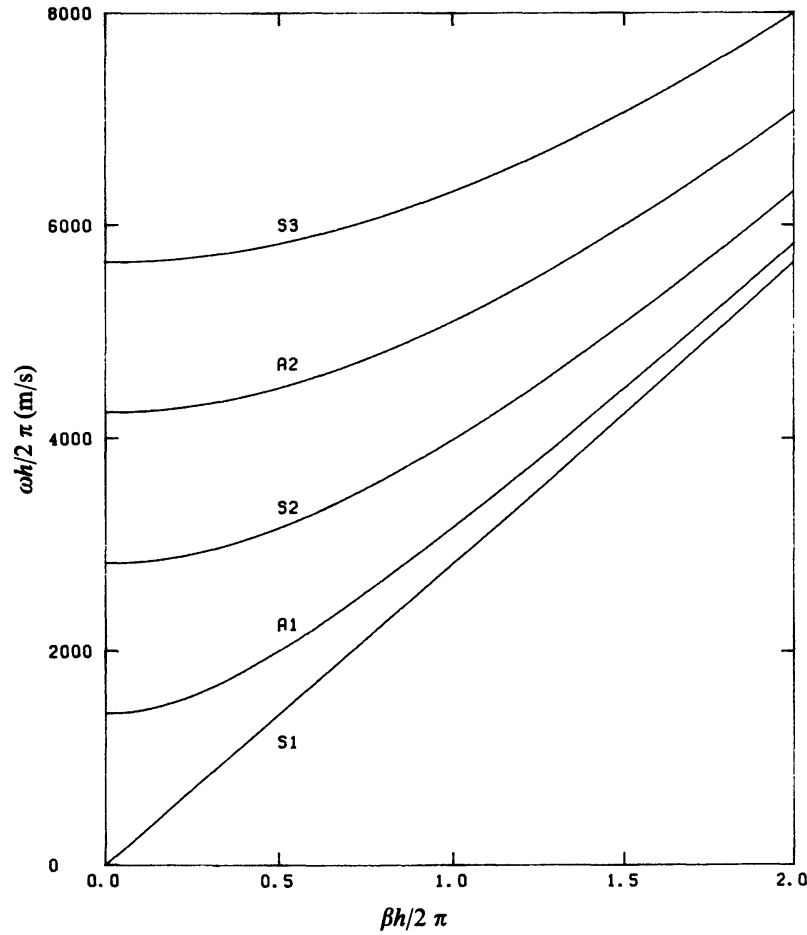

Fig. 5. - Dispersion curves for the modes of figure 2. Note that $(\beta h / 2 \pi)=h / \lambda$ and $(\omega h / 2 \pi)=(h / \lambda) V_{p}$.

The $\Delta V / V$ factor as calculated for the first three modes, $\mathrm{S} 1, \mathrm{~A} 1$ and $\mathrm{S} 2$ is shown in figure 6 . Since there are two free surfaces, there are two possible values for $\Delta V / V$ calculated at one surface depending on whether the other surface is short circuited (metallized) or not (not metallized). The values of $\Delta V / V$ peaks are considerably larger than the $0.22 \%$ for Bleustein-Gulyaev waves in a zinc oxide « infinite » substrate.

Another material with strong piezoelectricity is selenium. Selenium films grown on tellurium substrates
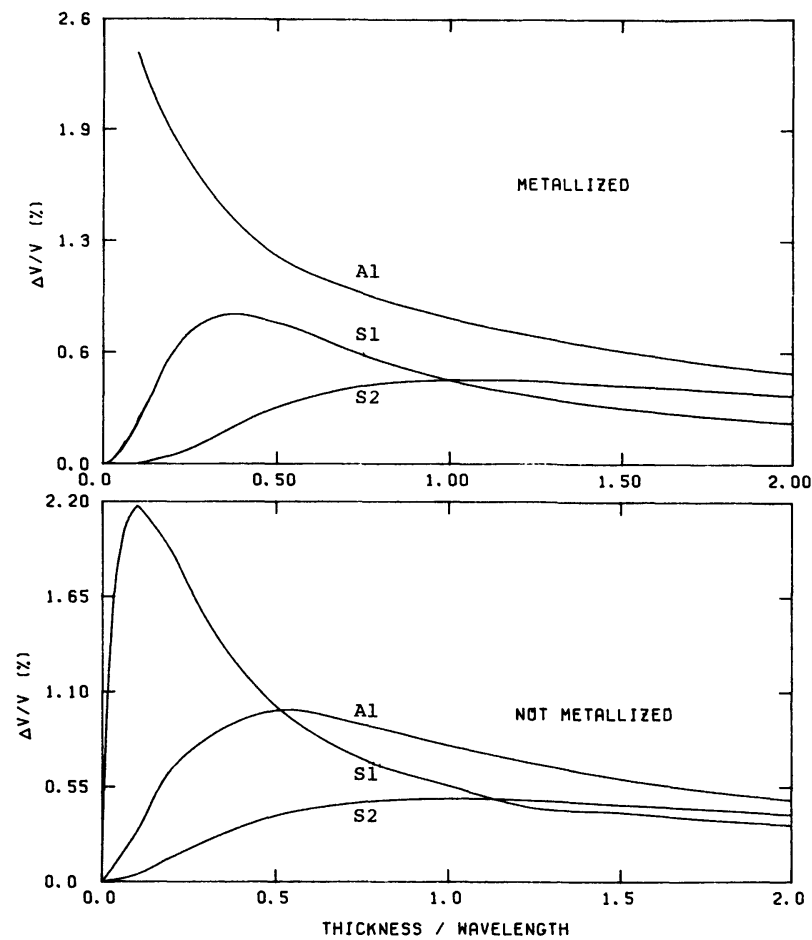

Fig. 6. $-\Delta V / V$ for the modes $\mathrm{S} 1, \mathrm{~A} 1$, and $\mathrm{S} 2$, of figure 2 , for the two metallization conditions.

have shown values of $\Delta V / V$ around $1 \%$ [7], comparable with the highest values obtained with $\mathrm{ZnO} / \mathrm{Si} \mathrm{SAW}$ structures. Selenium membranes may be prepared by etching the tellurium substrates onto which epitaxial

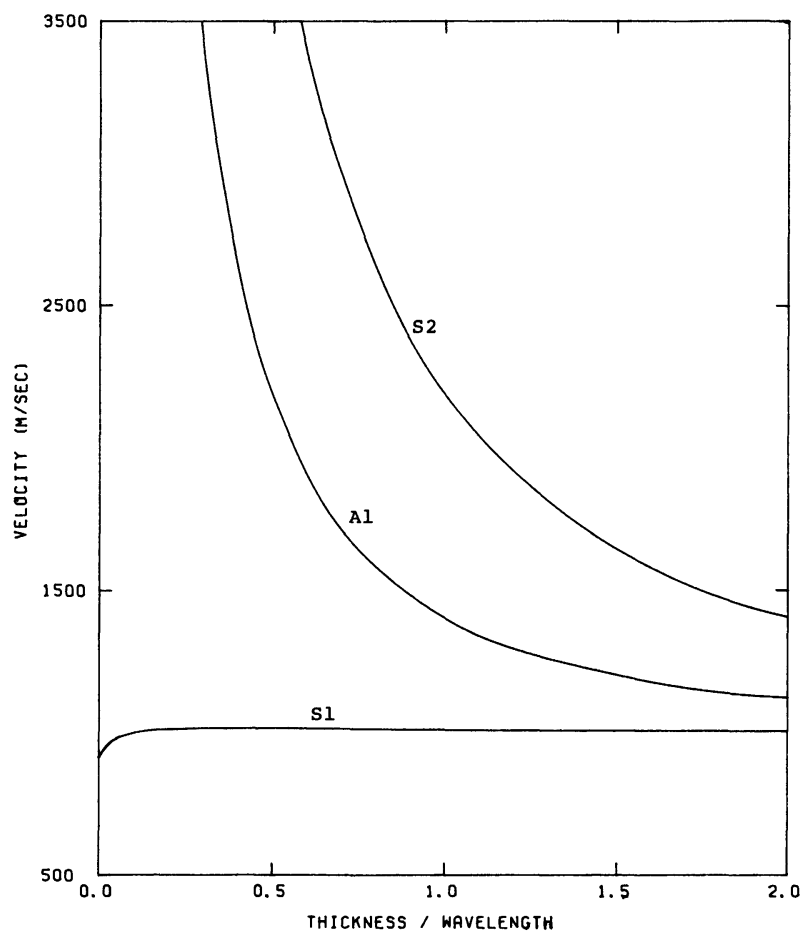

Fig. 7. - Wave velocity, versus $h / \lambda$, for the first three stiffened-shear modes in $Z$-cut selenium membranes. Propagation is along the $Y$-axis. 
selenium films have been grown. The velocity of each of the first three stiffened-shear modes in Se membranes is shown in figure 7. The membranes are $Z$-cut and

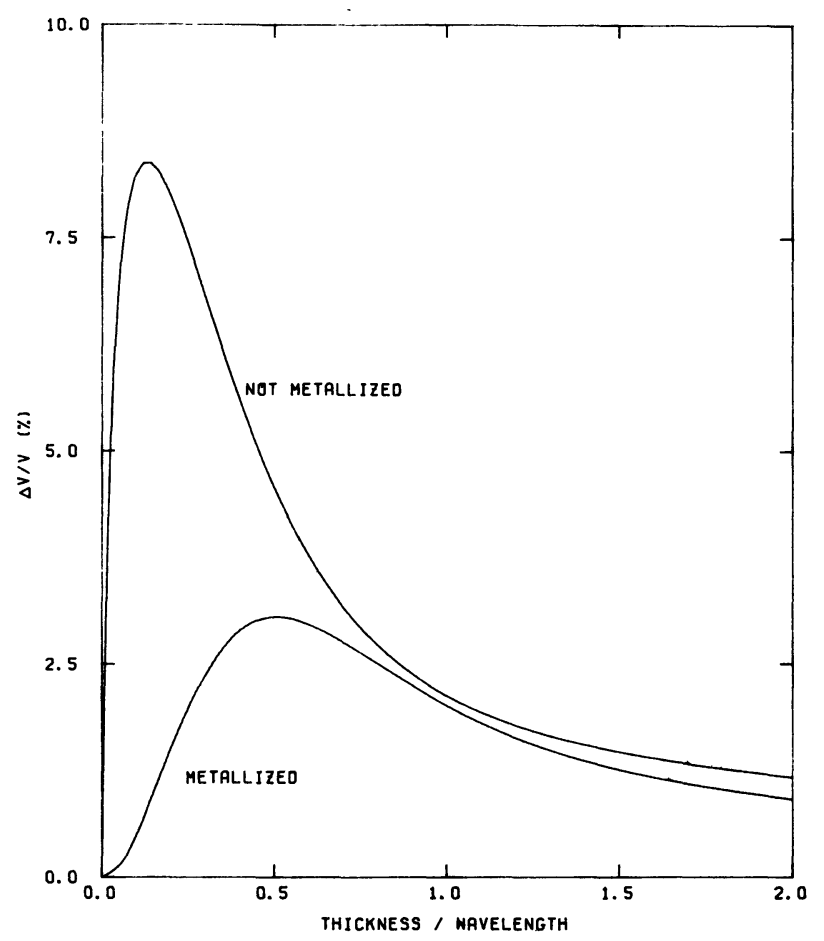

Fig. 8. $-\Delta V / V$ as a function of $h / \lambda$ for mode $S 1$ in a $Z$-cut selenium membrane. Propagation is along the $Y$-axis.

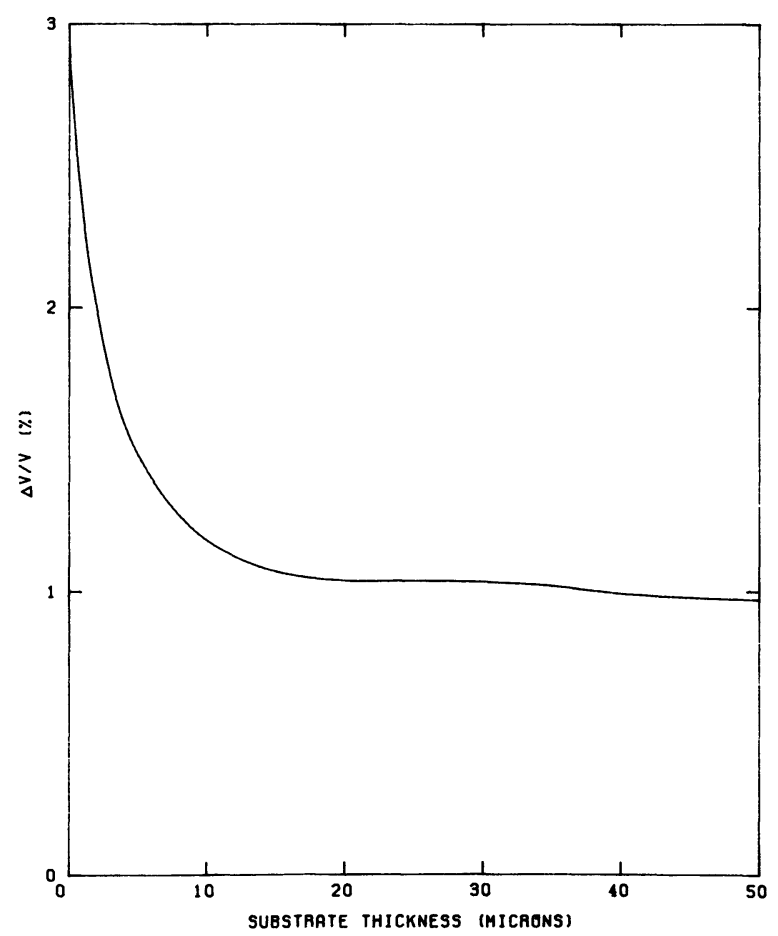

Fig. 9. $-\Delta V / V$ as a function of the substrate thickness in a $Z$-cut $\mathrm{Se} / \mathrm{Te}$ membrane for propagation along $Y$. The thickness of the selenium layer is $5 \mu \mathrm{m}$ and the frequency is $100 \mathrm{MHz}$. propagation is along the $Y$ axis. Like the $\mathrm{ZnO}$ membranes, the first symmetrical mode is an all-pass mode and is almost non-dispersive. The velocities are considerably lower than in $\mathrm{ZnO}$ membranes. The corresponding $\Delta V / V$ values ( $\mathrm{S} 1$ modes) are shown in figure 8 for the two metallization conditions. There is a large $\Delta V / V$ peak $(8.2 \%)$ for the non-metallized membrane at a thickness of about $1 / 8$ wavelength. A peak value of about $3 \%$ at half a wavelength is found for the metallized membrane.

With some of the tellurium kept as a supporting substrate for the selenium, the value of $\Delta V / V$ decreases. This behavior is shown in figure 9, for a selenium film thickness of $5 \mu \mathrm{m}$ at $100 \mathrm{MHz}$. Even with the decrease in the value of $\Delta V / V$, a large $1 \%$ is still possible for a substrate thickness of up to $50 \mu \mathrm{m}$.

\section{Stiffened-Lamb modes.}

These modes can propagate in structures having symmetry type 3 (Table I). One example is propagation along any direction parallel to the surfaces of a $Z$-cut $\mathrm{ZnO}$ membrane. As was shown in figure 4, there are two all-pass modes, A1 and S1. The first symmetrical mode S1 is of particular interest here because of its low-dispersion characteristic over a wide bandwidth, from very low frequencies to a frequency corresponding to $\mathrm{hf} \simeq 1500 \mathrm{~m} / \mathrm{s}$. The first antisymmetrical mode is also interesting because of two features : firstly the low values of velocity at the low hf region,

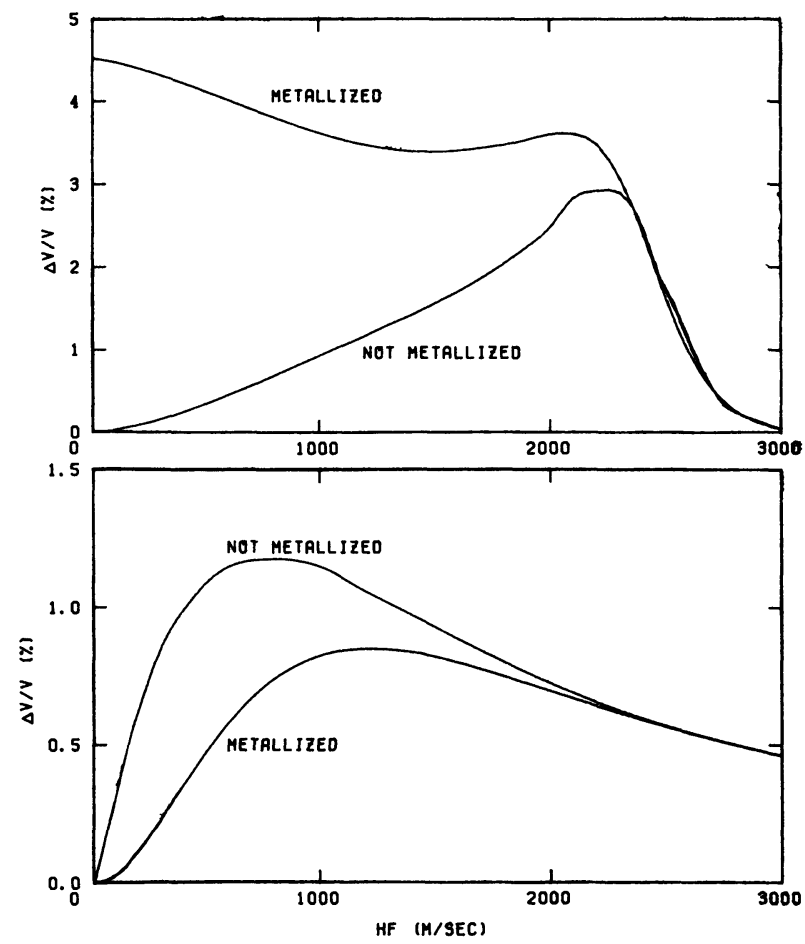

Fig. 10. $-\Delta V / V$ as a function of the thickness-frequency product, for the stiffened-Lamb modes in a $Z$-cut $\mathrm{ZnO}$ membrane. Upper graph mode S1, and lower graph mode A1. 
where velocity increases with frequency, and secondly a relatively low-dispersion bandwidth at higher values of $\mathrm{hf}(\mathrm{hf}>1700 \mathrm{~m} / \mathrm{s})$. The $\Delta V / V$ factors for these two modes are shown in figure 10 for the two metallization conditions. The first symmetrical mode in the metallized membrane has a high value of $\Delta V / V$ which remains high for up to $\mathrm{hf}=2200 \mathrm{~m} / \mathrm{s}$. Combined with the low velocity-dispersion, it makes this mode favorable for device applications requiring high coupling and low dispersion over a large bandwidth. This low dispersion is demonstrated in a different way by the flatness of the group velocity versus frequency curves shown in figure 11. It should be noted here that the thinner is the membrane, the lower is the velocity dispersion. This is because the group velocity is a function of the thickness frequency product hf.

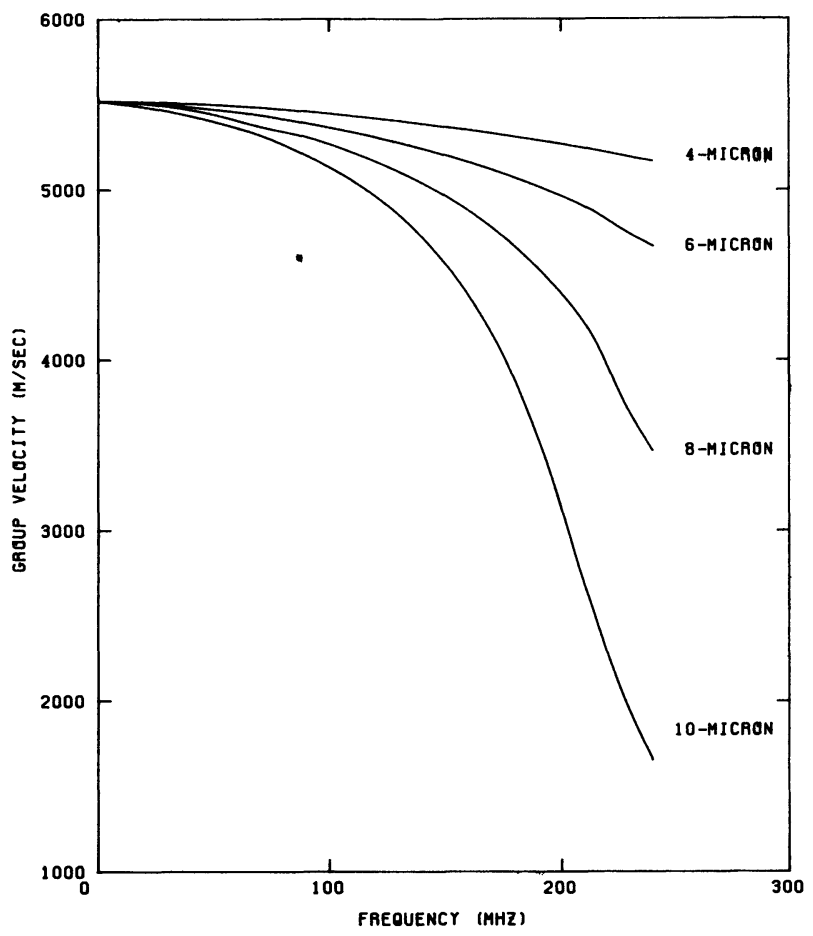

Fig. 11. - Group velocity versus frequency for the stiffenedLamb $\mathrm{S} 1$ mode in $\mathrm{Z}$-cut $\mathrm{ZnO}$ membranes of thicknesses $4,6,8$ and $10 \mu \mathrm{m}$.

4. 1 Composite membranes. - Practical $\mathrm{ZnO}$ devices operating with stiffened-Lamb mode can be fabricated by growing oriented $\mathrm{ZnO}$ ( $c$-axis normal or $Z$-cut) films on suitable substrates such as silicon or gallium arsenide (GaAs). The substrate is then thinned, or completely removed, to form a self-supporting thin membrane. In addition to mechanically supporting a thin film, a substrate can be used as an additional parameter to control important characteristics such as velocity, $\Delta V / V$ or bandwidth. For composite structures the modes will be called quasi-symmetrical or quasi-antisymmetrical. The wave velocities of four $\mathrm{ZnO} / \mathrm{Si}$ composite membranes are shown in figure 12 as functions of the thickness of the substrate. These

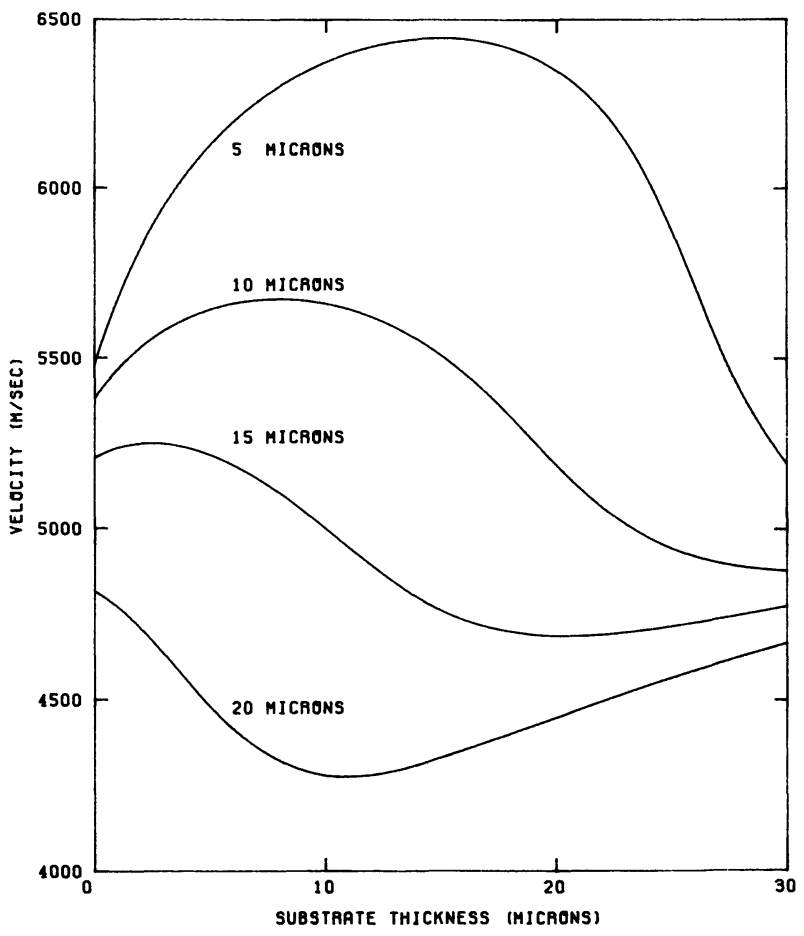

Fig. 12. - Velocity as a function of the substrate thickness in $\mathrm{ZnO} / \mathrm{Si}$ membranes. The thicknesses of the $\mathrm{ZnO}$ layers are $5,10,15$, and $20 \mu \mathrm{m}$ and the frequency is $100 \mathrm{MHz}$.

membranes are each composed of a $Z$-cut $\mathrm{ZnO}$ film over a (001) silicon substrate. The thickness of the films are $5,10,15$ and $20 \mu \mathrm{m}$ respectively and the frequency is $100 \mathrm{MHz}$. At this frequency the velocity of

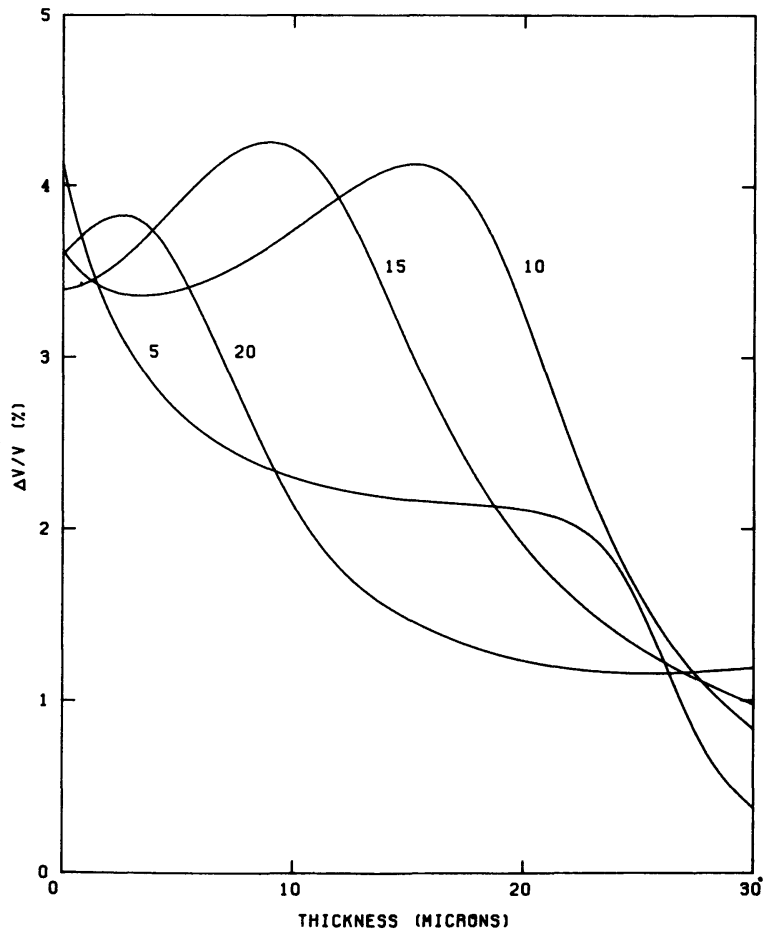

Fig. 13. $-\Delta V / V$ as a function of the substrate thickness for the four $\mathrm{ZnO} / \mathrm{Si}$ membranes of figure 12 . 


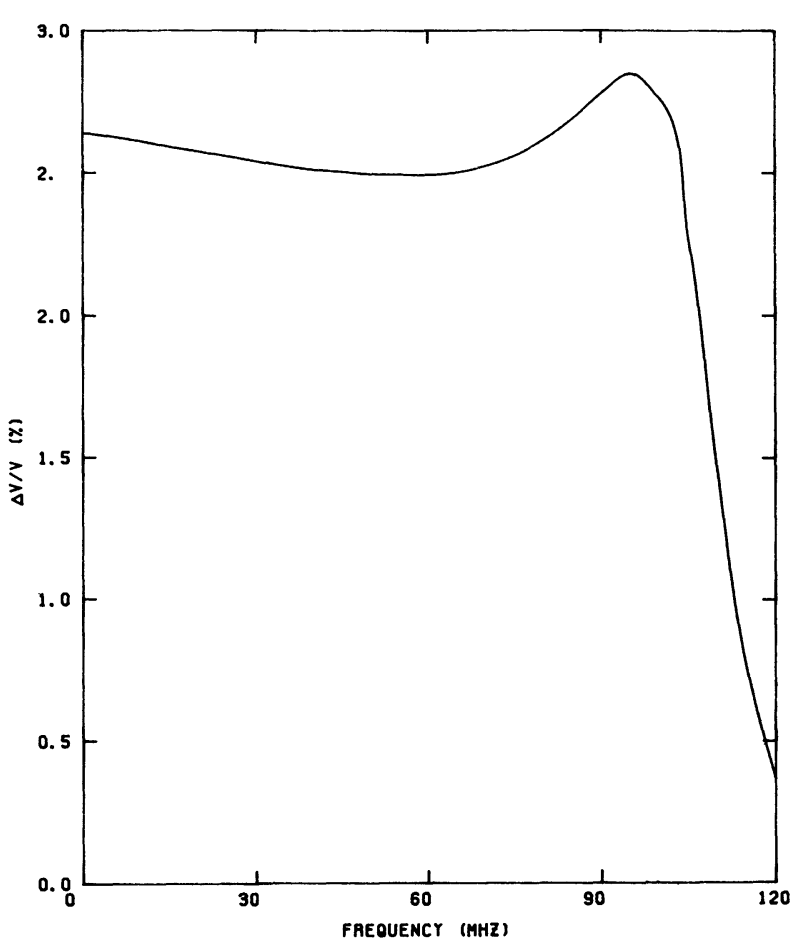

Fig. 14. $-\Delta V / V$ as a function of frequency for the composite membrane consisting of a $10 \mu \mathrm{m} \mathrm{ZnO}$ layer on a $10-\mu \mathrm{m}$ (001)-cut GaAs substrate, for the first quasi-symmetric mode. Propagation is in the [110] direction of the GaAs.

mode $\mathrm{S} 1$ in a simple $\mathrm{ZnO}$ membrane would vary from $5482 \mathrm{~m} / \mathrm{s}$ for a $5-\mu \mathrm{m}$ membrane to $4817 \mathrm{~m} / \mathrm{s}$ for a $20-\mu \mathrm{m}$ membrane, or a total change of $12 \%$. With the substrate the velocity of the quasi-symmetrical mode, as seen in figure 12 , can vary between a minimum of $4270 \mathrm{~m} / \mathrm{s}$ to a maximum of $6450 \mathrm{~m} / \mathrm{s}$ giving a wider adjustment range (ratio 3 to 2 ) for velocity (or delay time) to the device designer. The effect of the substrate on $\Delta V / V$ is even more noticable, as can be seen in figure 13. The curves are for the same four membranes, and the same frequency of $100 \mathrm{MHz}$. A final example is given in figure 14 , where the low-pass $\Delta V / V$ characteristics are shown for a composite $\mathrm{ZnO} / \mathrm{GaAs}$ membrane. The $\mathrm{ZnO}$ film and the GaAs substrate are $\mathrm{Z}$-cut, propagation is in the [110] direction of the GaAs. The $\mathrm{ZnO}$ layer is $10-\mu \mathrm{m}$ thick and the resulting bandwidth is seen to be about $100 \mathrm{MHz}$.

\section{Summary and conclusions.}

The coupling to piezoelectric stiffened plate modes, as quantified by $\Delta V / V$ has been shown to be as high as a few percent for both the stiffened-shear and the stiffened-Lamb modes in $\mathrm{ZnO}$ membranes. In $\mathrm{Se}$ membranes, $\Delta V / V$ 's in excess of $8 \%$ are found for the $\mathrm{S} 1$ stiffened-shear mode. In $\mathrm{ZnO}$ membranes the $\mathrm{S} 1$ stiffened-Lamb mode has a $4.5 \%$ and flat $\Delta V / V$ characteristic over a wide range of hf, from 0 to $2000 \mu \mathrm{m} \mathrm{MHz}(\mathrm{m} / \mathrm{s})$. The use of $\mathrm{ZnO} / \mathrm{Si}$ or $\mathrm{ZnO} / \mathrm{GaAs}$ composite membranes provides a means for adjusting the shape of the $\Delta V / V v s$. frequency characteristic to be either peaked or flat.

The examples given demonstrate the advantages of plate-mode devices for high frequency applications where a high $\Delta V / V$ and a high wave velocity are desirable. This combination is easily achieved with the first symmetrical (S1) stiffened-Lamb mode using $\mathrm{ZnO}$ on $\mathrm{Si}$ or on $\mathrm{GaAs}$ membranes. With these semiconductor supporting substrates plate-mode devices can be an integral part of an IC chip. The examples given in this paper are limited to two materials only for the sake of brevity and clarity, the computer program used to calculate the wave properties is capable of analysing multilayers, providing details of higher-order modes, and analysing orientations giving rise to any of the five symmetries listed in table I.

The authors acknowledge the support of the Natural Sciences and Engineering Research Council of Canada.

\section{References}

[1] Wagers, R. S., Plate Modes in Surface Acoustic Wave Devices, in Physical Acoustics 13, W. P. Mason and R. N. Thurston eds. (Academic Press, New York) 1977.

[2] Uozumi, K., Ohsone, K. and White, R. M., Generation and Detection of Ultrasonic Lamb Waves in a Thin Deposited Film by Using Interdigital Transducers, Appl. Phys. Lett. 43 (1983) 917.

[3] Chuang, C. T. and White, R. M., Coupling of Interdigital Transducer to Plate Modes in a Slotted Acoustically-Thin Membrane, IEEE Electron Device Letters EDL-4 (1983) 35.

[4] Nassar, A. A. and Adler, E. L., Propagation and Electromechanical Coupling to Plate Modes in Piezoelectric Composite Membranes, IEEE Ultrasonics Symposium Proc. (1983) 369.
[5] Nassar, A. A., Excitation of Surface Waves with Piezoelectric Layers, $\mathrm{Ph}$. D. Thesis, Department of Electrical Engineering, McGill University, Montréal, Québec, Canada, 1983.

[6] Farnell, G. W. and Adler, E. L., Elastic Wave Propagation in Thin Layers, in Physical Acoustics 9, W. P. Mason and R. N. Thurston eds. (Academic Press, New York) 1972.

[7] Nassar, A. A., Adler, E. L., Royer, D., Ravinet, P. and Dieulesaint, E., Electromechanical Coupling Factors for Surface Waves on Selenium and on Selenium Layers on Tellurium, IEEE Ultrasonics Symposium Proc. (1979) 654. 